\title{
CARBON DIOXIDE SENSITIVITY OF DYE COUPLING AMONG GLIA AND NEURONS OF THE NEOCORTEX ${ }^{1}$
}

\author{
B. W. CONNORS, ${ }^{2}$ L. S. BENARDO ${ }^{3}$ AND D. A. PRINCE \\ Department of Neurology, Stanford University School of Medicine, Stanford, California 94305
}

Received August 29, 1983; Revised December 5, 1983; Accepted December 13, 1983

\begin{abstract}
Among neocortical astrocytes and neurons, intracellular injection of the fluorescent dye Lucifer Yellow $\mathrm{CH}$ into single cells will often label multiple adjacent cells. It is possible that this intercellular dye movement occurs through gap junctions, which in several systems are sensitive to cytoplasmic acidification. In the present study we tested the effect of increased $\mathrm{CO}_{2}$ levels, a treatment expected to decrease intracellular $\mathrm{pH}\left(\mathrm{pH}_{\mathrm{i}}\right)$, on the prevalence of glial and neuronal dye coupling in neocortical slices. When $\mathrm{CO}_{2}$ levels were raised to $40 \%$ or $50 \%$, dye coupling among astrocytes was completely abolished. Under the same conditions, the prevalence of dye coupling among neocortical neurons of adult guinea pigs was significantly reduced to $18.7 \%$, compared to the control level of $32.3 \%$. Dye coupling among immature rat neocortical neurons, which normally occurs at relatively high rates, was not measurably affected by $\mathrm{CO}_{2}$ levels up to $50 \%$. The results suggest that coupling between cortical glia is very sensitive to cytoplasmic acidification. The relative insensitivity of neuronal coupling to $\mathrm{CO}_{2}$ may indicate either that the conductance of neuronal gap junctions is only weakly affected by $\mathrm{pH}_{\mathrm{i}}$ or that neuron-to-neuron dye passage occurs via other types of intercytoplasmic pathways.
\end{abstract}

A large variety of cell systems use gap junctions to effect specific cell-to-cell communication (Bennett and Goodenough, 1978). Gap junctions allow the intercytoplasmic diffusion of inorganic ions and small organic molecules (Loewenstein, 1981). The endogenous mechanisms regulating junctional permeability are not well understood. However, several recent studies have demonstrated that, at least in some systems, specific coupling may be modulated by intracellular $\mathrm{pH}\left(\mathrm{pH}_{\mathrm{i}}\right.$; Iwatsuki and Petersen, 1979; Giaume et al., 1980; Turin and Warner, 1980; Spray et al., 1981; Reber and Weingart, 1982). In each of these examples, acidification of the cell cytoplasm reversibly decreased or eliminated gap junctional conductance. The effectiveness of protons as junctional regulators is apparently not universal; several coupled systems appear to be immune, at least during part of their development (Turin and Warner, 1980;

\footnotetext{
${ }^{1}$ We wish to thank Drs. A. L. Harris and M. V. L. Bennett for valuable advice during the course of these studies, Cheryl Joo for manuscript preparation and Suzanne Lyon for assistance with the figures. This work was supported by National Institutes of Health Grant NS 06477.

${ }^{2}$ To whom correspondence should be addressed.

${ }^{3}$ Present address: Columbia University College of Physicians and Surgeons, 630 West 168th Street, New York, NY 10032.
}

Meyer and Revel, 1981; Spitzer, 1982; Scheutze and Goodenough, 1982).

There is evidence for specific intercellular coupling among both glia and neurons in the neocortex. Ultrastructural studies of astrocytic membranes have revealed frequent gap junctional profiles (Brightman and Reese, 1969; Landis and Reese, 1974), and fluorescent dye injected into single astrocytes is able to diffuse into adjacent glia (Gutnick et al., 1981). Neuron-to-neuron gap junctions have also been observed in developing and mature neocortex of several species (Mollgard and Moller, 1975; Sloper and Powell, 1978; Shoukimas and Hinds, 1978; Peters, 1980). Dye injections and indirect electrophysiological studies in neocortex of guinea pig and rat suggest that these junctions may be functionally significant (Gutnick and Prince, 1981; Connors et al., 1983). In spite of such anatomical and physiological indications of specific intercytoplasmic communication between cortical neurons, the data remain incomplete (see Connors et al., 1983 for discussion). The present study represents an effort to elucidate further the physiological significance of dye coupling between neocortical cells. We have tested the effectiveness of increased extracellular $\mathrm{CO}_{2}$ levels, a treatment expected to decrease $\mathrm{pH}_{\mathrm{i}}$, on the degree of fluorescent dye coupling between astrocytes and neurons. 


\section{Materials and Methods}

Our techniques of preparing and maintaining neocortical slices in vitro have been described in detail (Connors et al., 1982, 1983). Briefly, adult guinea pigs (300 to 350 $\mathrm{gm})$ or 6-day-old rats of either sex were decapitated, and their brains were rapidly removed and placed in ice-cold Ringer solution. A block of tissue was dissected from the sensorimotor area. Coronal slices $500 \mu \mathrm{m}$ thick were cut with a Mcllwain tissue chopper and were immediately placed in a recording chamber maintained at $36 \pm 1^{\circ} \mathrm{C}$. Intracellular recordings were made using thin-walled capillary tubing filled with a $5 \%$ solution of Lucifer Yellow CH (Aldrich Chemical Co., Inc.) in distilled water (150 to 200 megohms). Neurons were identified by the presence of action and synaptic potentials and high input resistances. Glia were characterized by high membrane potentials, inexcitability, lack of evoked synaptic potentials, and slow depolarizations during repetitive afferent stimulation, as previously reported for the neocortical slice preparation (Gutnick et al., 1981). Dye was injected by applying 900 -msec hyperpolarizing current pulses at 2 to $4 \mathrm{nA}$ at a frequency of $1 \mathrm{~Hz}$ using a bridge circuit. Injection periods ranged from 2 to $5 \mathrm{~min}$. Slices were fixed for $20 \mathrm{~min}$ in $4 \%$ buffered formalin $\left(22^{\circ} \mathrm{C}\right)$, dehydrated, cleared, and whole mounted for viewing under a Leitz epifluorescence microscope (Stewart, 1978).

In all cases slices were incubated for at least $1 \mathrm{hr}$ in control Ringer solution containing (in millimolar): $\mathrm{NaCl}$, $124 ; \mathrm{KCl}, 5 ; \mathrm{CaCl}_{2}, 2 ; \mathrm{MgSO}_{4}, 2 ; \mathrm{NaH}_{2} \mathrm{PO}_{4}, 1.25 ; \mathrm{Na}-$ $\mathrm{HCO}_{3}, 26$; dextrose, 10; they were equilibrated with $95 \%$ $\mathrm{O}_{2}+5 \% \mathrm{CO}_{2}(\mathrm{pH} 7.35$ to 7.40$)$. In high $\mathrm{CO}_{2}$ experiments the same medium was equilibrated with $60 \% \mathrm{O}_{2}+40 \%$ $\mathrm{CO}_{2}$ or $50 \% \mathrm{O}_{2}+50 \% \mathrm{CO}_{2}(\mathrm{pH} 6.2$ to 6.4$)$. There were no significant differences between the results obtained with the latter two conditions, and the data from each were pooled.

\section{Results}

Injections of Lucifer Yellow into guinea pig cortical cells with the physiological characteristics of glia usually resulted in a spherical array of stained astrocytes (cf. Gutnick et al., 1981). Staining was brightest in cell nuclei, which appeared to have a greater affinity for the dye than other cytoplasmic constituents. In many cases there was a central cell which was stained with relatively greater intensity than surrounding cells. Processes of these central cells could often be seen, and the cells usually had the morphological characteristics of protoplasmic astrocytes (Fig. $1 A$ ). The size of the glial aggregate was variable, ranging up to dozens of stained nuclei whose intensity appeared to diminish with distance from the central cell. Sixteen of 18 glial injections under control conditions resulted in labeling of such aggregates. In the two remaining cases only single, brightly stained astrocytes were recovered. In these cases the intensity of staining appeared greater than that of the central cells within stained glial aggregates.

Equilibration of the bathing medium with $60 \% \mathrm{O}_{2}+$ $40 \% \mathrm{CO}_{2}$ or $50 \% \mathrm{O}_{2}+50 \% \mathrm{CO}_{2}$ resulted in a complete loss of intercellular dye transfer. Following a 10-min or longer exposure to experimental solution, intracellularly injected Lucifer Yellow $\mathrm{CH}$ was confined to single glia in 28 of 28 cases. Such injections revealed glial morphology in much greater detail than that seen when multiple fills resulted following control injections (Fig. 1, $B$ to $D$ ). Discrete glial processes were always visible in the single filled cells. This presumably resulted from the much higher dye concentrations achieved when dye was confined to a single cell. Most of these dye-uncoupled glia had the morphological characteristics of protoplasmic astrocytes (cf. Takato and Goldring, 1979). When glia were injected in control medium and subsequently exposed to high $\mathrm{CO}_{2}$ medium, they remained dye-coupled.

Cells with glial characteristics were rarely encountered in 6-day-old rat cortex. However, we did successfully stain three such cells in control medium. Interestingly, all three dye injections yielded single stained astrocytes.

In a previous report (Gutnick and Prince, 1981), 8 of 11 neurons in the superficial layers $(<400 \mu \mathrm{m})$ of guinea pig sensorimotor cortex exhibited dye coupling. In this study, of 65 successful superficial (i.c., $<1000 \mu \mathrm{m}$ from the pial surface) neuronal injections of Lucifer Yellow, $21(32.3 \%)$ resulted in more than one stained neuron. Stained cells were usually pyramidal-shaped neurons, but nonpyramidal types were also recovered. Patterns of staining were similar to those reported by Gutnick and Prince (1981). Specifically, dye-coupled neurons were often arranged in vertical arrays with intersomatic distances ranging between $0 \mu \mathrm{m}$ and 200 to $300 \mu \mathrm{m}$. Dendritic fields overlapped in all cases. Coupled neuronal aggregates contained up to seven cells but usually consisted of two to three neurons. Although in some cases cells within an aggregate appeared to be stained at equal intensity, often one cell within a group fluoresced most brightly.

When slices were exposed to a bathing medium equilibrated with $60 \% \mathrm{O}_{2}+40 \% \mathrm{CO}_{2}$ or $50 \% \mathrm{O}_{2}+50 \% \mathrm{CO}_{2}$, neurons depolarized 30 to $40 \mathrm{mV}$ from normal resting potential. When neurons were injected under these conditions dye coupling was reduced, although not abolished (Fig. 2). In the acidified medium dye coupling was observed in 17 of 91 fills $(18.7 \%)$, and only 2 of these consisted of 3 or more cells. When the percentages of coupling in the control and high $\mathrm{CO}_{2}$-treated conditions were tested for equality (Sokal and Rohlf, 1969), they were found to be significantly different $\left(t_{s}=1.937, p<\right.$ 0.05 , one-tailed test). The single neurons $(n=74)$ obtained under experimental conditions were well stained cells of both pyramidal and nonpyramidal types.

In a previous study we observed a very high percentage of neuronal dye coupling prior to postnatal day 10 in the rat neocortex (Connors et al., 1983). In the present investigation, control dye injections in 6-day neocortical neurons resulted in multiply stained cells in 33 of 35 injections. The number of dye-coupled cells per aggregate ranged from two to nine (median of three). The pattern of dye-coupled neurons usually formed a columnar array with overlapping dendritic fields. Treatment of 6-dayold neocortex with $60 \% \mathrm{O}_{2}+40 \% \mathrm{CO}_{2}$ or $50 \% \mathrm{O}_{2}+50 \%$ $\mathrm{CO}_{2}$ did not measurably alter neuronal dye coupling. Among 27 injections of Lucifer Yellow under these conditions, 26 yielded multiply stained cells (Fig. 3). Dyecoupled aggregates contained from two to six cells each 

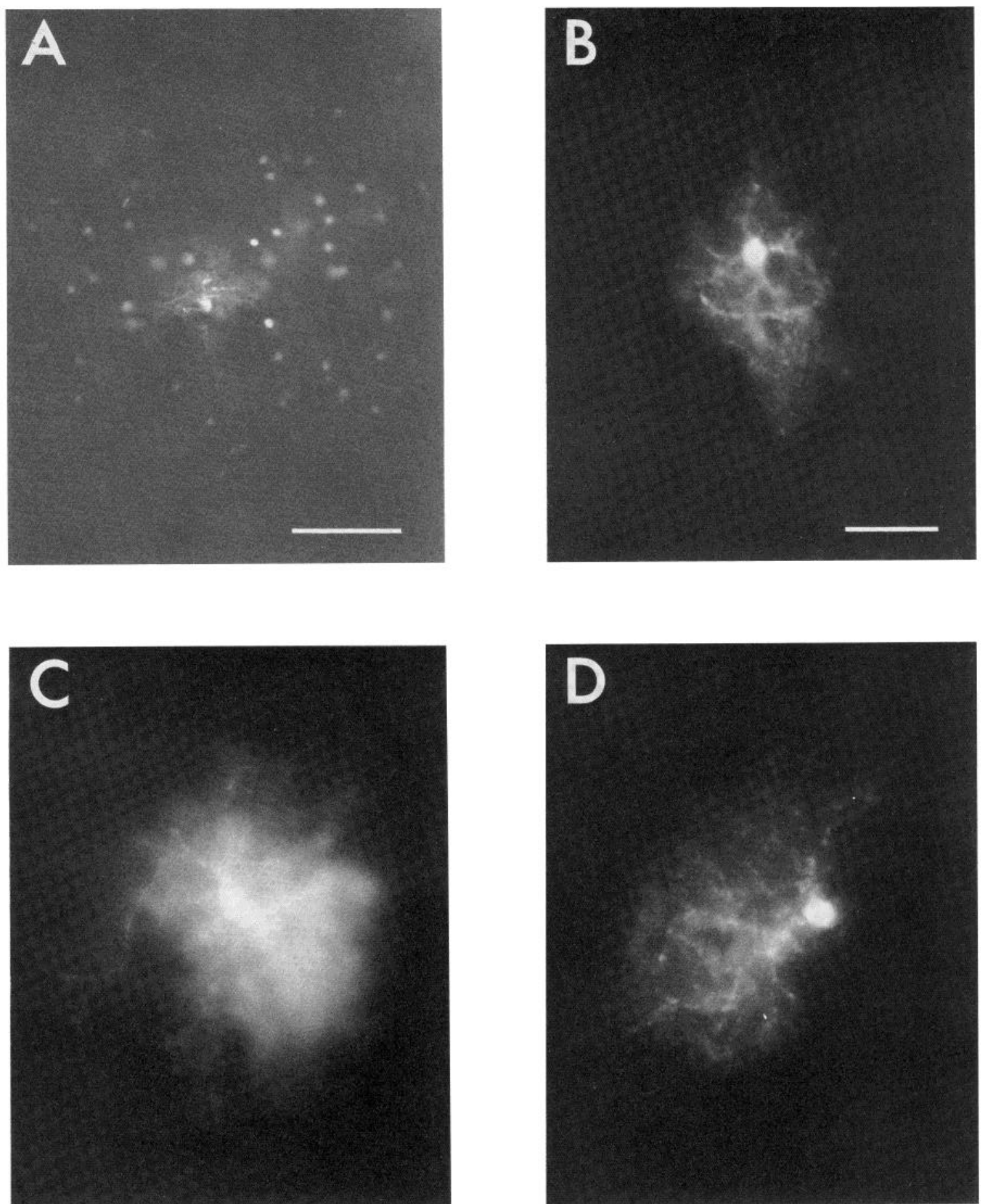

Figure 1. Effect of increased $\mathrm{CO}_{2}$ on astrocytic dye coupling. A, Dye coupling in control (5\%) $\mathrm{CO}_{2}$. Lucifer Yellow $\mathrm{CH}$ was injected into a single physiologically identified glial cell. Note the brightly stained central cell with faintly visible processes, surrounded by an aggregate of stained glial nuclei. Calibration bar $=100 \mu \mathrm{m}$. $B$ to $D$, Single stained astrocytes. Dye injections were made while bathing slices in media containing $40 \% \mathrm{CO}_{2}$. Examples from three separate injections in different slices are shown. Calibration bar $=20 \mu \mathrm{m}$ and applies to $B, C$, and $D$. 

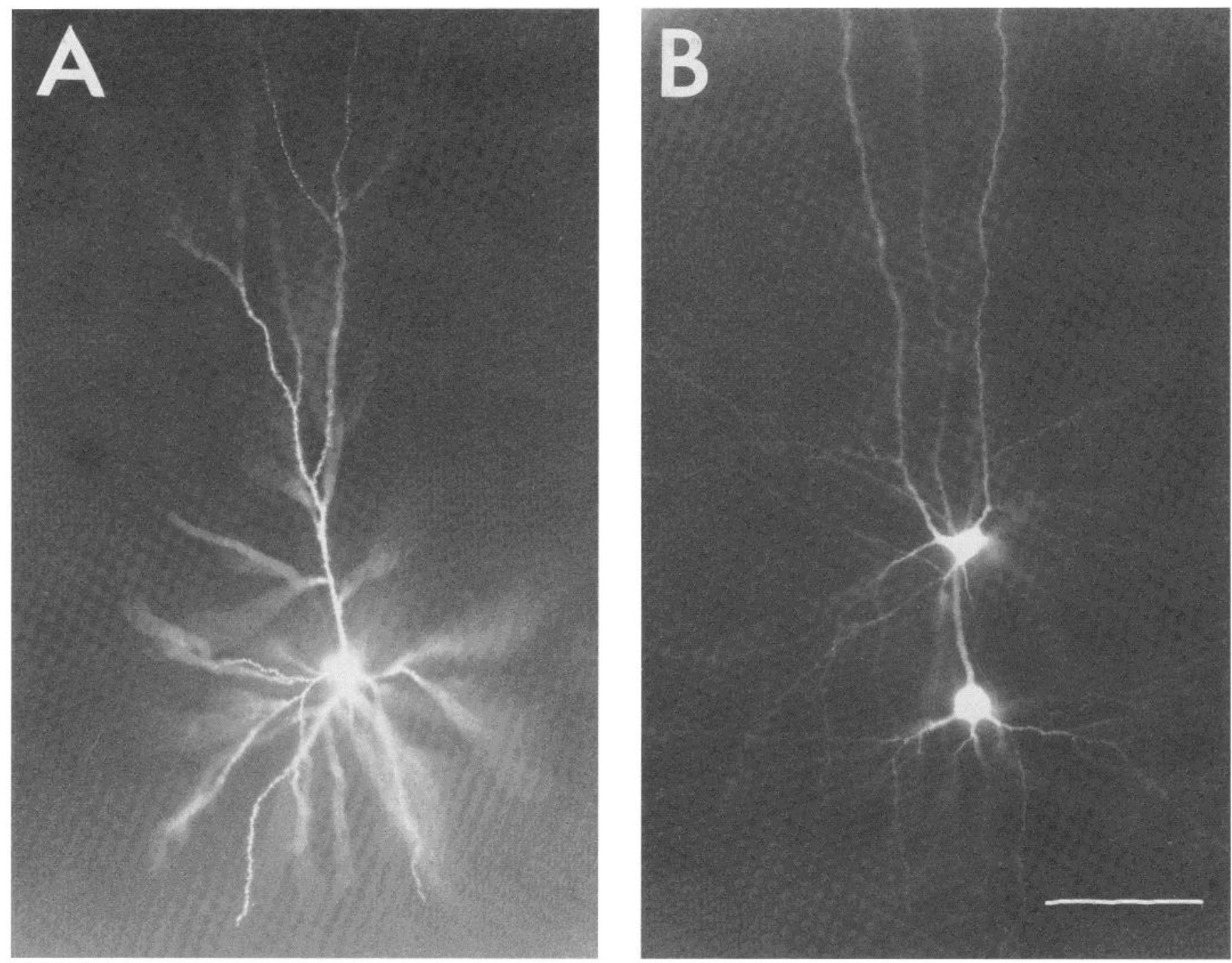

Figure 2. Dye-filled neurons in adult guinea pig cortex treated with $50 \% \mathrm{CO}_{2}$. A, Single dye-filled pyramidal cell. Calibration $b a r=100 \mu \mathrm{m}$. $B$, Two dye-coupled pyramidal cells resulting from a single neuronal injection. Calibration bar $=100 \mu \mathrm{m}$. $A$ and $B$ were obtained from different slices.

(median of three), and the cellular patterns and gross morphology were similar to control.

The effect of $\mathrm{CO}_{2}$ on the incidence of glial and neuronal dye coupling is summarized in Table I.

\section{Discussion}

Our results suggest that dye coupling among neocortical astrocytes is very sensitive to increased levels of $\mathrm{CO}_{2}$, whereas dye coupling among neurons in mature cortex is, under our experimental conditions, only partially sensitive. Dye coupling among neonatal neurons was not measurably reduced by levels of $\mathrm{CO}_{2}$ up to $50 \%$.

If it is assumed that interglial dye transfer occurs through specific gap junctions (see discussions in Gutnick et al., 1981; Kettenmann et al., 1983), then $\mathrm{CO}_{2}$ treatment must reduce junctional dye permeability. A major expected effect of increased $\mathrm{pCO}_{2}$ in both glia (Kimelberg et al., 1979) and neurons (Siesjo et al., 1972; Thomas, 1976; Sundt and Anderson, 1980) is a reduction in $\mathrm{pH}_{\mathrm{i}} . \mathrm{CO}_{2}$ permeates cell membranes with relative ease, undergoes hydration catalyzed by the enzyme carbonic anhydrase and dissociates to $\mathrm{H}^{+}$and $\mathrm{HCO}_{3}{ }^{-}$. It is impossible to predict the magnitude of steady-state $\mathrm{pH}_{\mathrm{i}}$ change in each tested cell type under our experimental conditions. This would require precise knowledge of the metabolic state of the cell, its intracellular buffering capacity, active $\mathrm{H}^{+}$extrusion mechanisms, and various internal and external substrate concentrations (Roos and Boron, 1981). In rat hippocampal slices under control conditions, Kass and Lipton (1982) estimated an overall $\mathrm{pH}_{\mathrm{i}}$ of about 7.25 by the DMO distribution method. In their study, complete anoxia for $10 \mathrm{~min}$ reduced $\mathrm{pH}_{\mathrm{i}}$ to about 6.5 ; thus, the hypoxia necessitated by our experimental protocol also may have contributed to an intracellular acidification.

Within the resolution of our method, dye was completely contained by the individual astrocyte membrane of each cell injected in high $\mathrm{pCO}_{2}$-containing media. Similar results have been obtained for another type of glia, the ependymal cells of turtle general cortex (Con- 

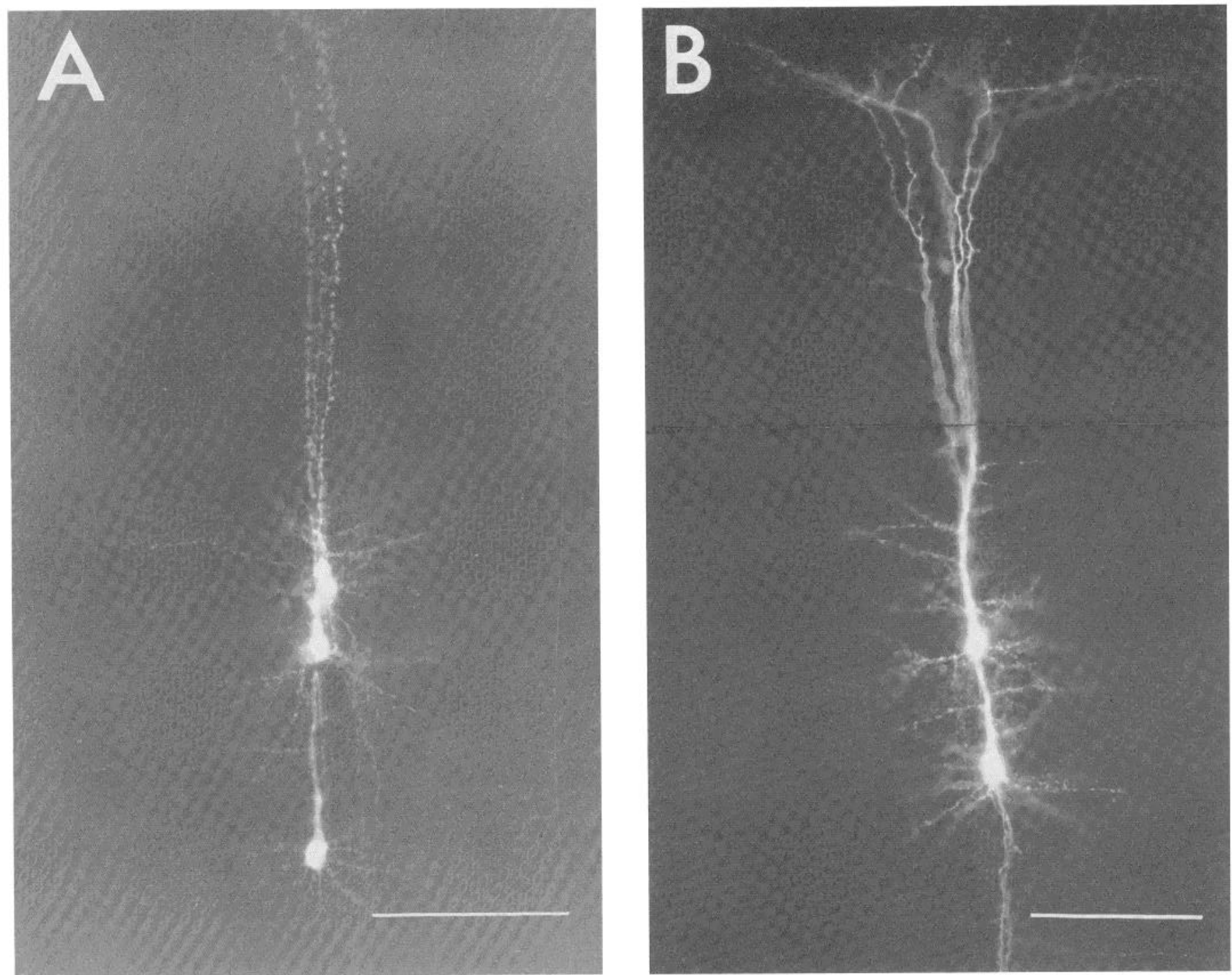

Figure 3. Dye-filled neurons in 6-day-old rat cortex treated with $50 \% \mathrm{CO}_{2}$. A, Five dye-coupled pyramidal cells resulting from a single neuronal injection. Calibration bar $=100 \mu \mathrm{m}$. $B$, Two dye-coupled pyramidal cells resulting from a single neuronal injection. This is a composite of two photomicrographs taken at different planes of focus. Calibration bar $=100 \mu \mathrm{m}$. $A$ and $B$ were obtained from different slices.

TABLE I

Incidences of dye coupling under control and $\mathrm{CO}_{2}$-treated conditions

\begin{tabular}{llcc}
\hline \multicolumn{1}{c}{ Cell Type } & Condition & $\begin{array}{c}\text { No. of Dye } \\
\text { Injections }\end{array}$ & $\begin{array}{c}\text { Percentage } \\
\text { Coupled }\end{array}$ \\
\hline Glia & Control & 18 & 88.9 \\
\multirow{2}{*}{ Mature neurons } & $\mathrm{CO}_{2}$ & 28 & 0 \\
& $\mathrm{Con}^{2}$ 6-day neurons & 65 & 32.3 \\
& $\mathrm{CO}_{2}$ & 91 & 18.7 \\
& $\mathrm{Con}^{2}$ & 35 & 94.3 \\
& $\mathrm{CO}_{2}$ & 27 & 96.3 \\
\hline
\end{tabular}

nors and Ransom, 1982). This suggests that the dye permeability of glial gap junctions, like that of certain other coupled cell systems (Schuetze and Goodenough, 1982; Jarrell, 1983), can be effectively abolished by low levels of $\mathrm{pH}_{\mathrm{i}}$. Uncoupling by $\mathrm{CO}_{2}$ might also be mediated by some less direct effect, such as a secondary change in intracellular $\left[\mathrm{Ca}^{++}\right]$(cf. Rose and Rick, 1978). Available evidence suggests that gap junctional channels fluctuate between a closed state and a single-conductance open state (Spray et al., 1982). Thus, it seems likely that glial gap junctions also become nonconductive to small inorganic ions when treated with $\mathrm{CO}_{2}$, leading to a simultaneous electrical uncoupling. Our occasional observation of dye-uncoupled astrocytes under normal recording conditions suggests that glial coupling may be very sensitive to the metabolic state of the tissue. This may explain the absence of astrocytic dye coupling in an in vivo study by Takato and Goldring (1979).

What might be the physiological significance of $\mathrm{pH}_{\mathrm{i}}$ sensitive glial coupling? There is reason to suspect that a syncytium of coupled astrocytes contributes to the spatial buffering of activity-dependent increases in extracellular $\left[\mathrm{K}^{+}\right]$(Orkand et al., 1966; Gardner-Medwin, 1983). A major tenet of this hypothesis is that astrocytes are electrically coupled to one another. If partial or total uncoupling were to occur, the regulation of extracellular $\left[\mathrm{K}^{+}\right]_{0}$ might be severely compromised. Large reductions 
of $\mathrm{pH}_{\mathrm{i}}$ can be brought about by hypercapnia, seizures, and metabolic disturbances (Siesjo, 1978). An impaired effectiveness of the spatial buffer for $\mathrm{K}^{+}$might contribute to neural dysfunction under these conditions.

Dye coupling among mature guinea pig neurons was significantly reduced, but not abolished, by $\mathrm{CO}_{2}$ treatment; dye coupling among immature rat neurons was unaffected by the same treatment. Using a different acidification protocol, M. J. Gutnick and R. Lobel-Yaakov (personal communication) recently found a highly significant reduction in dye coupling among guinea pig neocortical neurons. Several explanations might account for these disparate data. We are unable to measure $\mathrm{pH}_{\mathrm{i}}$ directly and thus confirm the level of acidification. Under the same experimental conditions, the resulting $\mathrm{pH}_{\mathrm{i}}$ in cortical neurons may differ from that of glia. Alternatively, the $\mathrm{pH}$ dependence of neuronal gap junctions may be much lower than that of glia. For example, coupling between Rohon-Beard neurons of Xenopus embryos (Spitzer, 1982) and rat hepatocytes (Meyer and Revel, 1981) appears to be insensitive to $\mathrm{CO}_{2}$, whereas Xenopus blastomeres (Turin and Warner, 1980) and chick lens cells (Schuetze and Goodenough, 1982) are uncoupled by $\mathrm{CO}_{2}$ only during certain stages of their development. In a comparative study of gap junctions, Spray et al. (1983) have shown that both the sensitivity to $\mathrm{pH}_{\mathrm{i}}$ and the apparent $\mathrm{pK}$ of the effect on channel conductance may vary widely among species and/or cell systems. It is also possible that neuronal dye coupling in neocortex, or some percentage of it, does not reflect coupling via specific gap junctions but derives from some form of artifactual intercellular membrane fusion. Such a process could conceivably occur from the tissue-slicing procedure or as a mechanical effect of microelectrode impalement. Further studies will be necessary to clarify these issues.

\section{References}

Bennett, M. V. L., and D. A. Goodenough (1978) Gap junctions, electrotonic coupling and intracellular communication. Neurosci. Res. Program Bull. 16: 373-486.

Brightman, M., and T. Reese (1969) Junctions between intimately apposed cell membranes in the vertebrate brain. $\mathrm{J}$. Cell Biol. 40: 648-677.

Connors, B. W., and B. R. Ransom (1982) Electrophysiological studies of ependymal cells of the turtle cortex. Soc. Neurosci. Abstr. 8: 237.

Connors, B. W., M. J. Gutnick, and D. A. Prince (1982) Electrophysiological properties of neocortical neurons in vitro. J. Neurophysiol. 48: 1302-1320.

Connors, B. W., L. S. Benardo, and D. A. Prince (1983) Coupling between neurons of the developing rat neocortex. $\mathrm{J}$. Neurosci. 3: 773-782.

Gardner-Medwin, A. R. (1983) Analysis of potassium dynamics in mammalian brain tissue. J. Physiol. (Lond.) 335: 393-426.

Giaume, C., M. E. Spira, and H. Korn (1980) Uncoupling of invertebrate electrotonic synapses by carbon dioxide. Neurosci. Lett. 17: 197-202.

Gutnick, M. J., and D. A. Prince (1981) Dye-coupling and possible electrotonic coupling in the guinea pig neocortical slice. Science 211: 67-70.

Gutnick, M. J., B. W. Connors, and B. R. Ransom (1981) Dyecoupling between glial cells in the guinea pig neocortical slice. Brain Res. 213: 486-492.

Iwatsuki, N., and O. H. Petersen (1979) Pancreatic acinar cells:
The effect of carbon dioxide, ammonium chloride and acetylcholine on intracellular communication. J. Physiol. (Lond.) 291: 317-326.

Jarrell, J. A. (1983) Reversible carbon dioxide-induced inhibition of dye-coupling in Necturus gallbladder. Am. J. Physiol. 244: C419-C421.

Kass, I. S., and P. Lipton (1982) Mechanisms involved in irreversible anoxic damage to the in vitro rat hippocampal slice. J. Physiol. (Lond.) 332: 459-472.

Kettenmann, H., R. K. Orkand, and M. Schachner (1983) Coupling among identified cells in mammalian nervous system cultures. J. Neurosci. 3: 506-516.

Kimelberg, H. K., S. Biddlecome, and R. S. Bourke (1979) SITS-inhibitable $\mathrm{Cl}^{-}$transport and $\mathrm{Na}^{+}$dependent $\mathrm{H}^{+}$production in primary astroglial cultures. Brain Res. 173: 111124.

Landis, D., and T. Reese (1974) Arrays of particles in freezefractured astrocytic membranes. J. Cell Biol. 60: 316-320.

Loewenstein, W. (1981) Junctional intercellular communication: The cell-to-cell membrane channel. Physiol. Rev. 61: 829-913.

Meyer, D. J., and J. P. Revel (1981) $\mathrm{CO}_{2}$ does not uncouple hepatocytes in the rat liver. Biophys. J. 33: 195a.

Mollgard, K., and M. Moller (1975) Dendrodendritic gap junctions (a developmental approach). Adv. Neurol. 12: 79-89.

Orkand, R. K., J. G. Nicholls, and S. W. Kuffler (1966) The effect of nerve impulses on the membrane potential of glial cells in the central nervous system of amphibia. J. Neurophysiol. 29: 788-806.

Peters, A. (1980) Morphological correlates of epilepsy: Cells in the cerebral cortex. In Antiepileptic Drugs: Mechanisms of Action, G. H. Glaser, J. K. Penry, and D. M. Woodbury, eds., pp. 21-48, Raven Press, New York.

Reber, W. R., and R. Weingart (1982) Ungulate cardiac Purkinje fibers: The influence of intracellular $\mathrm{pH}$ on the electrical cell-to-cell coupling. J. Physiol. (Lond.) 328: 87-104.

Roos, A., and W. F. Boron (1981) Intracellular pH. Physiol. Rev. 61: 296-434.

Rose, B., and R. Rick (1978) Intracellular $\mathrm{pH}$, intracellular free $\mathrm{Ca}$, and junctional cell-cell coupling. J. Membr. Biol. 44: 377415 .

Schuetze, S. M., and D. A. Goodenough (1982) Dye transfer between cells of the embryonic chick lens becomes less sensitive to $\mathrm{CO}_{2}$ treatment with development. J. Cell Biol. 92: $694-705$.

Shoukimas, G. M., and J. W. Hinds (1978) The development of the cerebral cortex in the embryonic mouse: An electron microscopic serial section analysis. J. Comp. Neurol. 179: $795-830$.

Siesjo, B. K. (1978) Brain Energy Metabolism, John Wiley \& Sons, New York.

Siesjo, B. K., J. Folbergrova, and V. MacMillan (1972) The effect of hypercapnia upon intracellular $\mathrm{pH}$ in the brain, evaluated by the bicarbonate-carbonic acid method and from the creatine phosphokinase equilibrium. J. Neurochem. 19: 2483-2495.

Sloper, J. J., and T. P. S. Powell (1978) Gap junctions between dendrites and somata of neurones in the primate sensorimotor cortex. Proc. R. Soc. Lond. Biol. 203: 39-47.

Sokal, R. R., and F. J. Rohlf (1969) Biometry, pp. 607-608, W. H. Freeman and Co., San Francisco.

Spitzer, N. C.(1982) Voltage and stage-dependent uncoupling of Rohon-Beard neurones during embryonic development of Xenopus tadpoles. J. Physiol. (Lond.) 330: 145-162.

Spray, D. C., A. L. Harris, and M. V. L. Bennett (1981) Gap junctional conductance is a simple and sensitive function of intracellular pH. Science 211: 712-715.

Spray, D. C., A. L. Harris, and M. V. L. Bennett (1982) 
Comparison of $\mathrm{pH}$ and calcium dependence of gap junctional conductance. In Intracellular $\mathrm{pH}$ : Its Measurement, Regulation and Utilization in Cellular Functions, pp. 445-461, Alan R. Liss, Inc., New York.

Spray, D. C., R. L. White, and M. V. L. Bennett (1983) Comparative physiology of the gap junction channel. Physiologist 26: A-106.

Stewart, W. W. (1978) Functional connections between cells as revealed by dye-coupling with a highly fluorescent napthalimide tracer. Cell 14: 741-759.

Sundt, T. M., and R. E. Anderson (1980) Umbelliferone as an intracellular $\mathrm{pH}$-sensitive fluorescent indicator and blood- brain barrier probe: Instrument action, calibration and analysis. J. Neurophysiol. 44: 60-75.

Takato, M., and S. Goldring (1979) Intracellular marking with Lucifer Yellow $\mathrm{CH}$ and horseradish peroxidase of cells electrophysiologically characterized as glia in the cerebral cortex of the cat. J. Comp. Neurol. 186: 173-188.

Thomas, R. C. (1976) The effect of carbon dioxide on the intracellular $\mathrm{pH}$ and buffering power of snail neurones. J. Physiol. (Lond.) 255: 715-735.

Turin, L., and A. E. Warner (1980) Intracellular pH in early Xenopus embryos: Its effects on current flow between blastomeres. J. Physiol. (Lond.) 300: 489-504. 